\title{
La nova «guerra de l'aigua» a Barcelona: austeritat, deute i participació privada
}

\author{
Hug March
}

Universitat Oberta de Catalunya. Internet Interdisciplinary Institute (IN3)

hmarch@uoc.edu

\section{Resum}

En aquest article es presenten de manera detallada els episodis més recents de reconfiguració del cicle metropolità i regional de l'aigua a Barcelona: la licitació del subministrador en alta Aigües Ter-Llobregat i la creació de l'empresa mixta Aigües de Barcelona, Empresa Metropolitana de Gestió del Cicle Integral de l'Aigua, SA. Aquests grans canvis s'emmarquen en unes polítiques d'austeritat i de privatitzacions legitimades pel deute creixent de l'Administració pública en un context de crisi econòmica. El deute acumulat per l'administració hídrica (Agència Catalana de l'Aigua) es pot entendre millor si es té en compte la reescalació de les polítiques mediambientals a Europa i una estructura de finançament insuficient del cicle de l'aigua en l'àmbit regional. Més enllà d'aquestes dues grans reconfiguracions, l'article presenta noves esferes del cicle de l'aigua que potencialment poden ser nínxols de mercat importants, com la gestió intel-ligent. Finalment es reflexiona críticament sobre quin impacte poden tenir aquests canvis per a la ciutadania i per al medi ambient.

Paraules clau: cicle urbà de l'aigua; privatització; reescalació; governança; crisi econòmica.

Resumen. La nueva "guerra del agua» en Barcelona: austeridad, deuda y participación privada

En este artículo se presentan de manera detallada los episodios más recientes de la reconfiguración metropolitana y regional del ciclo del agua en Barcelona: la licitación del proveedor en alta Aigües Ter-Llobregat y la creación de la empresa mixta Aigües de Barcelona, Empresa Metropolitana de Gestió del Cicle Integral de l'Aigua, SA. Estos grandes cambios se enmarcan en unas políticas de austeridad y de privatizaciones legitimadas por la creciente deuda de la Administración pública en un contexto de crisis económica. La deuda acumulada por la administración hídrica (Agència Catalana de l'Aigua) se puede entender mejor si se tiene en cuenta la reescalación de las políticas medioambientales en Europa y una estructura de financiación inadecuada del ciclo del agua a nivel regional. Más allá de estas dos grandes reconfiguraciones, el artículo presenta nuevas partes del ciclo del agua susceptibles de convertirse en importantes áreas de negocio, como la gestión inteligente. 
Finalmente se reflexiona críticamente sobre qué impacto pueden tener estos cambios en la ciudadanía y en el medio ambiente.

Palabras clave: ciclo urbano del agua; privatización; reescalación; gobernanza; crisis económica.

Résumé. La nouvelle "guerre de l'eau” à Barcelone: austérité, dette et participation privée

Cet article présente les changements récents du cycle métropolitain et régional de l'eau à Barcelone: la licitation de la société régionale Aigües Ter-Llobregat et la création de la société mixte Aigües de Barcelona, Empresa Metropolitana de Gestió del Cicle Integral de l'Aigua, S.A. Ces deux changements se sont produits dans le cadre de l'application des politiques d'austérité et de privatisation, ayant pour justification de combattre l'augmentation de la dette publique. La dette de l'Agence Catalane de l'Eau peut être mieux comprise si l'on regarde le ré échelonnage des politiques environnementales au niveau européen ainsi que le mauvais financement de la gestion de l'eau au niveau régional dans un contexte de crise économique. Au-delà de ces reconfigurations, l'article souligne d'autres sphères du cycle de l'eau qui commencent à exister sur le marché, comme par exemple la gestion intelligente. Finalement l'article évoque l'impact de ces changements sur les citoyens et sur l'environnement.

Mots-clé: cycle urbain de l'eau; privatisation; ré échelonnage; crise économique; gouvernance.

\section{Abstract. The new "water war" in Barcelona: austerity, debt and private participation}

This paper introduces the most recent developments in the metropolitan and regional reconfiguration of the water cycle in Barcelona: the lease of the raw water supplier Aigües Ter-Llobregat and the creation of the mixed-capital metropolitan firm Aigües de Barcelona, Empresa Metropolitana de Gestió del Cicle Integral de l'Aigua, S.A. In a context of economic crisis, both changes took place against the backdrop of austerity and privatization policies, which have been justified by the rocketing debt of the Catalan administration. The debt of the Catalan Water Agency can be better understood if we take into account the rescaling of environmental policies to the European level and the inadequate water financing model at a regional level. Beyond those reconfigurations I highlight other spheres of the water cycle that are beginning to attract the interest of private capital, such as smart management. Finally, we critically reflect upon the impact that those changes may have on the citizens as well as on the environment.

Keywords: urban water cycle; privatization; rescaling; economic crisis; governance.

\section{Sumari}

Introducció Noves fronteres per al capital privat en el

Crisi ambiental, crisi econòmica: l'estat anèmic de l'Agència Catalana de l'Aigua

Reconfiguració del subministrament en alta: la licitació d'Aigües Ter-Llobregat (ATLL)

Reconfiguració del subministrament en baixa i del sanejament: Aigües de Barcelona, Empresa Metropolitana de Gestió del Cicle Integral de l'Aigua, SA cicle de l'aigua: de les fonts alternatives a les solucions intel-ligents

Discussió

Conclusions

Agraïments

Referències bibliogràfiques 


\section{Introducció}

Com a activitat monopolística, el subministrament modern d'aigua ha estat un servei basic urbà atractiu per al capital privat. No obstant això, el seu paper ha estat desigual en diferents geografies i moments històrics. De manera resumida, podem dir que majoritàriament a Europa durant el segle xx, amb algunes excepcions, com França o la mateixa ciutat de Barcelona, el subministrament d'aigua urbà ha estat dominat pel sector públic, sigui local, regional o estatal. Tanmateix, en les últimes dècades del segle xx s'ha observat una intensificació del rol del capital privat en el cicle de l'aigua. Aquests moviments han estat legitimats mitjançant diferents discursos que operen a escala global i que han impulsat la gestió privada de l'aigua, sigui per la seva suposada major eficiència, per la necessitat d'inversions en la infraestructura per expandir el servei, o fins i tot per complir legislacions ambientals més exigents (vegeu Budds i McGranahan, 2003; Gialis et al., 2007; March i Saurí, 2013a). Aquests discursos han estat promoguts de manera important des d'instàncies supranacionals, com institucions econòmiques internacionals (Banc Mundial, Fons Monetari Internacional, etc.) o regionals (bancs de desenvolupament regional) (Bakker, 2003), subscrits per institucions polítiques com la Unió Europea i amb un paper actiu dels operadors de l'aigua privats internacionals (Hall i Lobina, 2007). A Barcelona, tanmateix, la participació privada en el subministrament modern ha tingut una trajectòria molt més dilatada i extensa. Així, des de mitjan segle xIx, l'empresa privada Aigües de Barcelona (amb diferents noms) ha tingut ininterrompudament el control del subministrament en baixa o, el que és el mateix, la distribució d'aigua a escala urbana (vegeu March Corbella, 2010). Durant el segle XIX i començaments del xx, altres companyies privades, i fins i tot l'Ajuntament, subministraven aigua a parts de la ciutat. No obstant això, a començaments del segle xx la Societat General d'Aigües de Barcelona es va refermar amb el control en règim monopolístic de tota la ciutat, després d'adquirir els diferents subministradors i guanyar la partida a l'Ajuntament, que perseguia la municipalització del servei (Martín Pascual, 2009; March, 2013a). Excepcionalment, l'empresa va perdre el control sobre el cicle hídric urbà durant la Guerra Civil Espanyola, quan la companyia va ser col-lectivitzada pels treballadors en el marc de les diferents col-lectivitzacions produïdes a Catalunya (Gorostiza et al., 2013). Amb l'arribada de la dictadura de Franco, la companyia va ser retornada als antics propietaris (banquers) i va ampliar el seu poder sobre el cicle de l'aigua urbà gràcies a la concessió que li va donar l'Estat per extreure i tractar aigua superficial del riu Llobregat a començaments dels anys cinquanta del segle passat. Posteriorment, l'Ajuntament de Barcelona li va cedir la gestió de l'aigua que va arribar del transvasament del Ter l'any 1966.

Al llarg del segle xx, la companyia va ampliar el seu rang d'actuació a diferents municipis veïns. Amb l'arribada de la democràcia i la reorganització metropolitana de l'àrea de Barcelona es va constituir l'Entitat Metropolitana 
de Serveis Hidràulics i Tractament de Residus, que posteriorment va donar lloc a l'Entitat Metropolitana de Medi Ambient (EMA). A partir d'aquest moment, els municipis metropolitans van cedir les seves competències en el subministrament hídric a aquest organisme, que és el que directament negocia amb les companyies, entre les quals destaca Aigües de Barcelona (Agbar), les condicions de concessió del subministrament urbà.

D'altra banda, el subministrament en alta $^{1}$ en l'àmbit metropolità de Barcelona a uns cinc milions de ciutadans, l'ha dut a terme, de manera majoritària, l'empresa pública Aigües Ter-Llobregat (ATLL). Tanmateix, podem considerar que Agbar ha tingut una relació directa amb el subministrament en alta, ja que extreu i tracta aigües superficials del riu Llobregat a través de la planta potabilitzadora de Sant Joan Despí, inaugurada el 1957. D’altra banda, també ha extret recursos subterranis al Llobregat i al Besòs, i durant un breu període després de la seva inauguració va gestionar la planta dessaladora del Prat de Llobregat (tot i que la propietat era d'ATLL).

Fins a finals de 2012, Agbar gestionava el subministrament en baixa (per delegació de l'EMA) de la ciutat de Barcelona i de la majoria dels municipis metropolitans, i comprava majoritàriament l'aigua (a part de les fonts pròpies mencionades anteriorment) a l'empresa pública ATLL (subministrament en alta). Recentment, però, s'han materialitzat canvis molt rellevants, tant en la gestió en alta com en la gestió en baixa. D'una banda, el subministrador regional ATLL va ser licitat a finals de $2012 \mathrm{i}$ adjudicat, de manera polèmica, a la companyia Acciona per cinquanta anys. D'altra banda, l'any 2013 s'ha produït la creació de l'empresa publico-privada Aigües de Barcelona, Empresa Metropolitana de Gestió del Cicle Integral de l'Aigua, SA, que subministra aigua a una gran part dels municipis de l'àrea metropolitana. Aquests canvis s'han produit guiats per unes polítiques d'austeritat que es justifiquen en el dèficit i el deute acumulat pel sector públic i la necessitat de capital per continuar fent operatiu el cicle metropolità. El deute acumulat pel sector públic es pot entendre si s'analitzen les grans inversions requerides en els darrers vint anys per complir les directives europees i el finançament limitat del cicle de l'aigua. Aquestes reconfiguracions, tanmateix, han estat contestades tant per les empreses privades competidores com pels moviments veïnals i ecologistes, per motius ben diversos, $i$ algunes romanien sotmeses a processos judicials en el moment de redactar aquest treball. Una vegada el cicle integral de l'aigua ha passat virtualment a mans privades, l'article tracta sobre les noves fronteres de negoci en la gestió de l'aigua i se centra en la gestió intel-ligent. Finalment, es discuteixen les implicacions que aquestes reconfiguracions poden tenir en el ciutadà $\mathrm{i}$ en el medi ambient, i s'apunta una agenda de recerca que explori aquestes qüestions.

1. La gestió dels recursos hídrics des del seu origen fins als dipòsits dels municipis o, en altres paraules, la captació d'aigua no potable, el tractament per convertir-la en potable i la seva conducció fins als dipòsits urbans. 
Crisi ambiental, crisi econòmica: l'estat anèmic de l'Agència Catalana de l'Aigua

A finals del segle xx es va crear l'Agència Catalana de l'Aigua (ACA) per substituir l'antiga Junta d'Aigües i la Junta de Sanejament, i amb el record del conflicte de la Guerra de l'Aigua que va tenir lloc a la dècada dels anys noranta del segle passat a la Barcelona metropolitana (vegeu Domene i Saurí, 2012). Aquest organisme té competències directes sobre la planificació i la regulació del cicle hidrològic de les conques internes, incloent-hi el sanejament. Per fer front a les grans inversions requerides, es va acordar que l'Agència s'autofinançaria a través de l'anomenat "cànon de l'aigua», una taxa associada al consum d'aigua domèstic $\mathrm{i}$ industrial. Amb el pas dels anys, s'ha observat una clara dissociació entre els ingressos i les despeses de l'Agència (March i Saurí, 2013a), que l'ha obligat a recórrer a l'endeutament. Tot i no tenir un paper directe en el subministrament d'aigua (dut a terme per altres empreses públiques o privades), el deute econòmic acumulat per l'ACA ha estat un factor clau en la reconfiguració del cicle de l'aigua, especialment del subministrament en alta de la regió metropolitana de Barcelona.

En el context de la pitjor crisi econòmica soferta pel nostre país, i per extensió pel sud d'Europa en les darreres dècades, el sector públic ha experimentat una forta reconfiguració per les polítiques d'austeritat de despesa i de privatització. A Catalunya, a finals de 2011 es van aprovar les lleis òmnibus de simplificació, agilitat i reestructuració administrativa i de promoció de l'activitat econòmica. Entre els canvis previstos s'incloïen canvis dins l'ACA i la possibilitat que el sector privat gestionés l'empresa pública Aigües Ter-Llobregat (ATLL). El Govern català insistia en el dramàtic deute acumulat en el cicle de l'aigua i la impossibilitat de refinançar-se a través dels mercats internacionals.

En aquesta secció exposarem de manera resumida la progressió d'aquest deute acumulat, així com alguns dels motius pels quals s'ha incrementat. Entre d'altres, destaca l'aplicació a marxes forçades i sense un finançament adequat de les directives europees relacionades amb el cicle hidrològic. És clar, tanmateix, que la crisi econòmica ha accelerat la intensitat del problema de sobreendeutament, ja que s'han tancat de manera dràstica les vies de crèdit de què l'ACA havia disposat fins llavors.

A finals de 2011, el deute a llarg termini de l'ACA s'aproximava al seu màxim legal de 1.500 milions d'euros, mentre que el d'ATLL estava al voltant dels 679 milions d'euros. Aquests deutes representaven aproximadament el 20 per cent de les necessitats financeres del Govern català per a l'any 2011. El cost anual, només en interessos, de refinançar aquest deute ha superat 50 milions anuals ( $\mathrm{i}$ en algun any s'ha aproximat als 100 milions d'euros) i és superior, en el cas de l'ACA, als seus costos de personal laboral (per a una versió més extensa d'aquests arguments vegeu March i Saurí, 2013a).

Així doncs, darrere la «inevitabilitat» de reconfigurar el cicle de l'aigua argumentada pel Govern català, ens trobem amb unes dades objectives de deute creixent tant de l'ACA com d'ATLL. Tanmateix, el que no és tan evident 
és la lectura oficial que s'ha fet de les causes d'aquest deute, que s'ha atribuït inequívocament a una gestió «desastrosa» de l'executiu català entre 2003 i 2010 (el dos tripartits entre el PSC, ERC i ICV). Com ja s'ha argumentat en treballs previs (March i Saurí, 2013a), aquesta lectura és polèmica i de curtes mires, $\mathrm{i}$ intencionadament $\mathrm{o}$ inintencionadament oblida altres factors que superen l'escala temporal i geogràfica anterior, molt especialment l'anomenada «modernització ecològica» (March, 2013b) del cicle de l'aigua «imposada» a Europa en les darreres dues dècades i fruit de la reescalació de la governança del cicle de l'aigua cap a les escales europees (i també cap a les escales regionals). En aquest sentit, des de l'accés d'Espanya a la Unió Europea l'any 1986, les directives europees han tingut un paper clau en la millora ambiental a l'Estat en general, $\mathrm{i}$ més particularment en el cicle de l'aigua. Directives com la de sanejament urbà de 1991, la d'aigua potable de 1998 o la Directiva marc de l'aigua, de l'any 2000, han millorat indubtablement la qualitat dels nostres ecosistemes aquàtics continentals i costers. Per exemple, només cal dir que quan Espanya va entrar a la UE el tractament de les aigües residuals només arribava al 30 per cent de la població (EEA, 2010). Tanmateix, aquesta adaptació a marxes forçades als estàndards europeus també ha tingut unes conseqüències financeres importants sobre la gestió pública del cicle de l'aigua. A Catalunya, més específicament, la directiva sobre aigües residuals de 1991 va impulsar la construcció massiva de depuradores, així com l'ampliació de les plantes existents per fer front al nivell de tractament requerit en funció de la població servida (per a diferents horitzons temporals: 1998, 2000 i 2005). Part d'aquestes inversions, sobretot a la dècada dels anys noranta del segle xx, i també en menor manera a la primera dècada del segle xxI, va ser cofinançada amb fons europeus. D'altra banda, la Directiva marc de l'aigua de l'any 2000 obligava els estats europeus a aconseguir un bon estat ecològic de les seves masses continentals d'aigua per a l'any 2015. Aquesta darrera directiva ha condicionat profundament les polítiques de l'aigua en els àmbits estatal i català. El Pla de gestió de conca fluvial de Catalunya, aprovat pel Govern català a finals de 2010, és l'instrument que ha de determinar les mesures i accions necessàries per desenvolupar els objectius de planificació hidrològica d'acord amb les premisses de la Directiva marc de l'aigua al districte de la conca fluvial de Catalunya. El pla preveia la necessitat d'invertir uns 9.500 milions d'euros durant el període 2010-2015 per complir les demandes europees, xifra que no es podrà cobrir atesa la conjuntura econòmica. Actualment, s'està en la fase de revisió del pla, que s'ha de publicar a finals de 2015.

D'altra banda, mentre que aquesta reescalació de la governança del cicle de l'aigua cap a l'esfera europea i la demanda de més protecció ambiental poden explicar les grans despeses associades al cicle de l'aigua en els darrers vint anys (una part de les quals va ser finançada amb fons europeus), no és possible entendre la crisi de deute de l'administració hídrica sense tenir en compte el model particular de finançament d'aquestes inversions i despeses, que constitueix l'altra cara de la moneda de la crisi de l'aigua a Catalunya. Com ja s'ha comentat, durant la creació de l'ACA es va acordar que seria autosuficient econòmicament 
a través del cànon de l'aigua i no rebria transferències econòmiques (en termes generals) de la Generalitat o de l'Estat. L'excepció va ser el període 2006-2010, quan hi va haver una transferència directa de la Conselleria de Medi Ambient de 150 milions d'euros. De fet, com es pot veure amb més detall a March i Saurí (2013a), on s'han analitzat detalladament els pressupostos de l'ACA des de la seva creació, de mitjana el cànon de l'aigua només ha cobert la meitat de les despeses i inversions públiques en el cicle de l'aigua dutes a terme per l'ACA. Això ha tingut com a resultat un dèficit anual important i la necessitat de l'ACA de recórrer als mercats financers (més enllà de les transferències de fons de cohesió o de fons regionals de la UE o de la mateixa Generalitat, com hem comentat anteriorment) per quadrar els desequilibris entre ingressos $\mathrm{i}$ despeses. També s'ha recorregut, d'altra banda, a l'augment sostingut del cànon. De fet, la situació ha esdevingut tan extrema que l'any 2012 el pagament del deute (incloent-hi els interessos) requeria al voltant del 70 per cent dels ingressos obtinguts pel cànon de l'aigua. Així doncs, mentre que el cànon ha augmentat en els darrers anys, aquests increments han anat a parar «virtualment» a retornar el deute i els costos derivats d'aquest, en lloc de revertir d'una manera més gran en la millora del funcionament del cicle de l'aigua.

Paral.lelament a aquestes inversions per complir els dictats europeus, també hem d'afegir els costos econòmics dels darrers episodis de sequera (2005 i especialment 2007-2008), que van tenir un impacte molt important en la societat catalana (per a una descripció detallada de l'episodi de sequera, vegeu Aldomà-Boixadé, 2012 o March i Saurí, 2013b). Finalment, també s'ha observat un descens del consum en bona part de la Barcelona metropolitana en els darrers anys (vegeu AMB, 2013). Per bé que això són bones notícies per al medi ambient, ja que ha disminuït la pressió sobre els ecosistemes aquàtics, paradoxalment ha pogut tenir un impacte menys positiu en les finances de l'ACA, que s'ha traduiit en un descens dels ingressos pel cànon de l'aigua.

Així doncs, per complir amb les exigències ambientals europees (en els darrers vint anys), i per fer front als darrers episodis de sequera, l'ACA (i en certa manera ATLL) ha hagut d'invertir en el cicle de l'aigua per sobre de les seves possibilitats financeres, limitades per l'estructura de recuperació de costos (en front d'un descens dels ingressos per un descens del consum) i la no-transferència de recursos addicionals. Això té com a resultat l'acumulació d'un deute conjunt superior als 2.000 milions d'euros i ha donat arguments al paradigma dominant, que es tradueix en austeritat i privatitzacions i la reconfiguració del cicle de l'aigua, amb una transferència de poder i control cap al sector privat.

\section{Reconfiguració del subministrament en alta: la licitació d'Aigües Ter-Llobregat (ATLL)}

Davant la delicada situació financera de l'Administració catalana, el Govern català va endegar el 2012 el concurs de licitació del subministrador en alta regional Aigües Ter-Llobregat (ATLL) (recordem que a finals de 2011 l'aprovació de les lleis òmnibus de flexibilització de l'Administració ja obrien 
les portes a fer aquest pas). La licitació es va fixar per una durada de cinquanta anys per 995,5 milions d'euros, dels quals una part s'hauria d'avançar al començament del contracte, i per una inversió de 126 milions d'euros en el cicle de l'aigua en els deu anys següents.

Per bé que al principi diferents operadors es van posicionar per participar en el procés de licitació, finalment només es van presentar dos consorcis al concurs: un primer consorci liderat per Acciona (39\% capital), conjuntament amb el banc d'inversions brasiler BTG Pactual (39\% capital) i petits inversors; i un segon liderat per Agbar (25\% capital) conjuntament amb el fons d'inversió canadenc Caisse de Dépots (33\%), l'australià First State (30\%), el grup CASSA $\mathrm{i}$ altres petits inversors (12\%) (GWI, 2012a).

El 6 de novembre de 2012 es va adjudicar la gestió d'ATLL al consorci liderat per Acciona. Es va acordar que aquest consorci avançaria 300 milions d'euros d'entrada i aportaria la resta al llarg de cinquanta anys (uns 700 milions). Tanmateix, aquesta decisió va ser el principi d'un conflicte entre empreses privades i l'Administració que s'ha judicialitzat, i que en el moment de redactar aquest article encara no s'havia resolt. Davant l'adjudicació inicial, el consorci liderat per Agbar va acudir a l'Organ Administratiu de Recursos Contractuals de Catalunya (OARCC) per presentar un recurs contra l'acceptació de la proposta del consorci liderat per Acciona, argumentant diferents incompliments al plec de condicions de l'oferta d'aquest consorci. A començaments de desembre de 2012, l'OARCC va acceptar parcialment el recurs contra l'adjudicació del contracte. Tanmateix, el 27 de desembre de 2012, ATLL, Concessionària de la Generalitat de Catalunya, SA (liderada per Acciona), va signar el contracte que estableix la gestió en règim de concessió durant cinquanta anys d'ATLL a partir de l'1 de gener de 2013. La totalitat dels 995,5 milions d'euros es va anotar als ingressos de la Generalitat de 2012 i va reduir el dèficit català de 2012 en mig punt (encara que només en va ingressar al voltant de 300 milions, ja que els restants havien de ser amortitzats en els cinquanta anys següents). Un dia després de l'inici de la concessió, l'OARCC va emetre un dictamen en què donava parcialment la raó al recurs interposat per Agbar. Dels diferents arguments presentats, se'n va donar un de bo: que la companyia adjudicatària va presentar un programa d'execució d'obres i d'inversions que no complia els requisits del plec de condicions. La resolució executiva de l'OARCC apel.lava a invalidar l'oferta presentada per Acciona. Aquesta decisió de l'OARCC va ser recorreguda per la Generalitat i per Acciona al Tribunal Superior de Justícia de Catalunya (TSJC), i van demanar que se suspengués de manera cautelar l'efectivitat de la resolució de l'OARCC fins que no hi hagués una sentència en ferm. Paral.lelament, Agbar va demanar a la Generalitat que complís la resolució i, en conseqüència, li adjudiqués la gestió d'ATLL, cosa que la Generalitat no va fer.

El mes de març de 2013, el TSJC va denegar la paralització cautelar de la resolució de l'OARCC argumentant que aquesta era executiva i basant-se en jurisdicció europea sobre els mecanismes àgils de suspensió de contractes públics. A l'abril, la Generalitat va presentar un recurs de reposició al TSJC 
contra la interlocutòria d'aquest tribunal en considerar que l'oferta d'Agbar tampoc no complia les condicions establertes per l'OARCC. A part dels costos financers i de les indemnitzacions que s'haurien de pagar al consorci liderat per Acciona (si assumim que el retorn dels 300 milions que el consorci havia fet efectius al començament del contracte serien coberts pel nou concessionari), la Generalitat argumentava que l'oferta d'Agbar suposaria un increment als usuaris de 956 milions d'euros a causa del preu de venda d'aigua ofert, que era més alt que el del consorci Acciona.

El 19 de juliol de 2013, el TSJC va confirmar el rebuig dels recursos de la Generalitat de Catalunya i d'Acciona i va reafirmar la validesa de la decisió adoptada per l'OARCC. El refús dels recursos per part del TSJC va generar una situació d'incertesa sobre l'estat legal de la concessió d'ATLL. Així, el TSJC argumentava, segons el diari El Pais (19 de juliol de 2013), que «l'estat actual de les coses porta a una primera hipòtesis consistent en el fet que el servei sigui concedit al segon licitant [és a dir, al consorci liderat per Agbar]»o «si aquesta hipòtesi no prospera, el servei haurà de ser objecte d'una nova licitació, ja que el marc normatiu imposa la gestió per concessió». En aquest sentit, el Govern català va estudiar la possibilitat d'un recurs de cassació davant el Tribunal Suprem d'Espanya, però, en tot cas, amb aquesta decisió quedava el dubte de si Acciona estava legalment autoritzada a prendre el control d'ATLL. Posteriorment, el Gabinet Jurídic de la Generalitat de Catalunya, que depèn de Presidència, va presentar en data de 22 de juliol un informe al TSJC on es demanava la nul.litat absoluta de la resolució de l'OARCC argumentant que els fonaments en què es va basar aquesta última per prendre una decisió eren erronis. Per calmar les inquietuds dels accionistes i dels socis financers, la mateixa companyia Acciona va presentar un comunicat el 23 de juliol afirmant que la sentència no anul.lava l'adjudicació del contracte, que continuava sent efectiu legalment ${ }^{2}$.

En el moment d'escriure aquest article encara no hi havia una resolució en ferm del litigi, però, tal com revelava el diari El País (9 d'octubre de 2013) citant un document oficial, en el cas de perdre el litigi, la Generalitat es comprometia a retornar els 298 milions ingressats just després de l'adjudicació, els costos de les inversions fetes i els costos financers de l'operació, i a retre una compensació pels beneficis que li hauria donat el negoci. Segons citava el diari, el document preveia, en cas que la licitació fos revocada, que s'adjudiqués ATLL a un nou concessionari privat o bé que retornés al sector públic.

La important "guerra" per l'aigua en alta, és a dir, per la gestió d'ATLL, entre Acciona i Agbar, rau en la important xifra de negoci que es pot fer gestionant de manera monopolística el subministrament regional. Per veure la importància del negoci, només cal citar les dades aportades per Acciona aparegudes al diari Ara (14 de maig de 2013), que va valorar el negoci a ATLL en 6.000 milions d'euros.

2. Vegeu Acciona (2013). "The ATLL management contract is valid and will remain in force». 23 de juliol de 2013. <http://www.acciona.com/news/the-atll-management-contract-is-valid-and-will-remain-in-forces. 


\section{Reconfiguració del subministrament en baixa i del sanejament: Aigües de Barcelona, Empresa Metropolitana de Gestió del Cicle Integral de l'Aigua, SA}

Paral-lelament al procés de licitació del subministrament en alta al llarg de 2012 i 2013 s'han produït canvis molt importants en la gestió en baixa, és a dir, en el subministrament urbà d'aigua. Aquest darrer procés també ha estat guiat per disputes entre diferents parts interessades i sotmès als veredictes de la justícia, començant per la polèmica sobre l'estat de la concessió a Agbar del subministrament d'aigua a la ciutat de Barcelona (vegeu per exemple Balasch, 2012).

Amb aquesta polèmica de fons, a finals de 2012 l'Àrea Metropolitana de Barcelona (AMB) va engegar la creació, juntament amb Agbar, d'una empresa de capital mixt per gestionar el cicle integral de l'aigua, incloent-hi el subministrament d'aigua en baixa i la gestió del sanejament, en règim de concessió per trenta-cinc anys a l'Àrea Metropolitana (amb l'excepció d'alguns municipis $\mathrm{amb}$ altres règims concessionals). En aquesta nova societat, Agbar posseiria el $85 \%$ del capital i el restant 15\% seria de l'AMB. Encara que Agbar ja té un monopoli quasi absolut pel que fa al subministrament metropolità (sigui directament a través d'Aigües de Barcelona o de Sorea, amb algunes excepcions, com per exemple al Prat de Llobregat), no passa el mateix amb el sanejament, on l'Empresa Metropolitana de Sanejament, SA (EMSSA) ha tingut un paper molt important.

La justificació que es va donar per a la reconfiguració del subministrament en baixa va ser que es volia salvar el «forat negre» en què podria caure el finançament del cicle de l'aigua a l'AMB (vegeu per exemple La Vanguardia, 29 d'octubre de 2013). La manca d'un concurs públic en aquesta nova concessió a l'empresa mixta de nova creació va provocar les queixes no només d'associacions veïnals i ecologistes i partits polítics, sinó també d'altres companyies privades del sector de l'aigua. Mentre que l'AMB (vegeu GWI, 2012b) mantenia que l'obertura d'un concurs no era necessària, ja que la creació d'una societat mixta no alterava els drets i les concessions existents en el cicle hidrològic, segons la plataforma Aigua és Vida, aquest procés responia a la necessitat de regularitzar la incerta situació contractual d'Ägbar en l'àmbit metropolità esmentada anteriorment.

La nova companyia havia de començar a operar el gener de 2013, però els diversos contenciosos oberts van portar a la suspensió cautelar del seu funcionament. A començaments de 2013, la Generalitat de Catalunya va recórrer la creació d'aquesta societat al TSJC per invasió de competències en la gestió de l'aigua en alta. Prèviament, les companyies privades Aguas de Valencia, Aqualia, Sociedad Española de Abastecimientos i Acciona ja havien presentat recursos a la creació, sense contracte previ i sense concurs, de la nova companyia metropolitana liderada per Agbar, i van reclamar que se suspengués el procés de manera cautelar.

Més enllà de l'Administració pública autonòmica i les empreses competidores, diverses organitzacions ciutadanes també van portar el procés als tribunals. 
El febrer de 2013, la plataforma Aigua és Vida va portar a la Fiscalia Anticorrupció la constitució d'aquesta societat mixta metropolitana i va denunciar l'existència d'indicis de prevaricació per part de l'AMB i de l'Ajuntament de Barcelona, així com apropiació indeguda per part d'Agbar d'infraestructures públiques. D'altra banda, un particular també va presentar un recurs al TSJC on argumentava que el funcionament de la nova companyia encariria substancialment el preu que els ciutadans paguen per l'aigua.

El maig de 2013, el TSJC va desestimar la petició de les empreses privades i de la Generalitat de suspendre cautelarment l'activitat de la nova empresa mentre no hi hagués una decisió final del TSJC. Això va donar peu al fet que finalment es pogués constituir aquell mateix mes la nova societat a falta de l'aprovació del Govern català. Amb aquest acord, Agbar rebria uns interessos anuals del 7,5\% pel traspàs de la infraestructura a la nova societat i un 3,5\% pel seu saber fer (know how) (La Vanguardia, 21 de maig de 2013).

Paral-lelament, el maig de 2013, l'ACA va acordar obrir un procés de revisió de totes les concessions d'obtenció d'aigua que Agbar té en el sistema TerLlobregat. D'acord amb l'article 65.1 de la Llei d'aigües espanyola de l'any 1985 , totes les concessions es poden revisar quan hi ha indicis que les condicions en què es van donar les concessions han canviat substancialment. Segons el diari El País, una trentena de concessions podrien ser retirades i retornades a l'ACA (El Pais, 13 de maig de 2013). En aquest sentit, l'ACA argumentava que tant els pous de l'aqüífer del Llobregat com la planta de captació i tractament d'aigua superficial de Sant Joan Despí (que data de 1953) s'haurien d'incloure en la gestió en alta, i conseqüentment els hauria de gestionar ATLL. A banda, moltes d'aquestes concessions van ser atorgades abans del restabliment de la democràcia (fins i tot algunes daten del segle XIX). Des de llavors, segons defensa l'ACA, s'han produït canvis substancials en la gestió de l'aigua en l'àmbit metropolità: hi ha hagut un increment notable de les infraestructures i sobretot ha tingut lloc la unió del sistema Ter amb el Llobregat.

El juny de 2013, la nova companyia va poder començar a operar gràcies al fet que el Govern català va retirar el recurs del TSJC després que es fessin certes modificacions en l'acord entre Agbar i l'AMB pel que fa al subministrament en alta. El nou acord es va aprovar amb els vots favorables de CiU i el PSC, l'abstenció d'ERC i PP i l'oposició d'ICV. Finalment, el juliol de 2013, el TSJC va ratificar la desestimació dels recursos de les companyies privades contra l'acord entre Agbar i l'AMB. Tanmateix, encara no s'ha resolt la qüestió de si els pous del Llobregat i la planta de tractament d'aigües de Sant Joan Despí formen part finalment de la xarxa en alta o de la xarxa en baixa.

\section{Noves fronteres per al capital privat en el cicle de l'aigua: de les fonts alternatives a les solucions intel.ligents}

Podríem pensar que, després d'aquestes dues grans reconfiguracions de poder sobre el cicle hídric de Barcelona, la iniciativa privada ja no té més marge de maniobra per controlar noves esferes en el cicle urbà de l'aigua. Així doncs, 
el control durant cinquanta anys (provisional) d'Acciona sobre ATLL i la reafirmació del monopoli metropolità per trenta-cinc anys més sobre la gestió en baixa d'Agbar podrien ser llegits com «el final de la història» pel que fa a l'interès del capital privat pel cicle urbà i regional de l'aigua. Tanmateix, aquesta visió està allunyada de la realitat. De fet, durant la redacció de l'article va circular la notícia que la Generalitat estava estudiant la privatització de les depuradores a Catalunya per poder reduir el dèficit en el pressupost per al 2014. Queda per analitzar com es materialitza (si es materialitza) tal reconfiguració.

Més enllà d'aquesta possible nova privatització, a continuació es vol mostrar que el cicle urbà de l'aigua encara té moltes fronteres de negoci per al capital privat. En aquest sentit, la utilització de membranes no tan sols per tractar aigua marina o salobres (dessalatge), sinó també per reutilitzar aigües grises o residuals i contaminades avança a gran velocitat. Això obre noves possibilitats tant per a les companyies que subministren la tecnologia com per a les mateixes companyies d'aigua tradicionals. Paral-lelament, aquestes mateixes tecnologies, juntament amb l'aprofitament d'aigües pluvials, poden esdevenir una eina per als ciutadans per disminuir el seu grau de dependència dels sistemes centralitzats si aquestes s'utilitzen a la llar (vegeu per exemple Domènech i Saurí, 2010; Domènech, 2011 o Domènech et al., 2013).

A part de les fonts alternatives, en el present treball volem introduir altres propostes més incipients que han estat poc explorades acadèmicament. En aquest sentit, a Barcelona, per exemple, trobem una aposta clara d'Agbar, a través de la seva filial Aquology, per l'anomenat paradigma de les «ciutats intelligents». Un exemple d'aquesta aposta serien els comptadors intel.ligents, que permeten fer lectures a temps real i a distància dels consums tant en llars com en equipaments municipals, i d'aquesta manera es poden proposar programes de gestió més eficients. Actualment, Aquology té proves pilot en diferents municipis, entre els quals podem destacar a Catalunya Castelldefels i Gavà $o$ Tarragona, amb 10.000 i $55.000^{3}$ comptadors intel.ligents respectivament. En la línia dels comptadors intel.ligents també es pot destacar, per exemple, AQMOS (Aqualogy Management Operating System), una plataforma que integra informació tècnica sobre el subministrament $i$ que està destinada a millorar la coordinació operacional i permetre una resposta automatitzada a les necessitats específiques del client per gestionar els recursos existents d'una manera més eficient.

En el marc de la gestió urbana intel-ligent, Agbar està signant acords amb diferents municipis catalans. Per exemple, col-labora amb l'Ajuntament de Barcelona per transformar la ciutat en un laboratori d'experimentació i innovació amb l'anomenat Smart City Campus-22@ com a eix principal. Com es pot llegir a la seva pàgina web, aquest projecte serà «un clúster de nova generació per educar, investigar i desenvolupar solucions per a les smarts cities que es puguin aplicar a tot el món», on "s'ubicaran empreses,

3. <http://www.agbar.es/pdf/45.pdf>. 
universitats, emprenedors i centres d'investigació de les TIC, l'ecologia i l'urbanisme» ${ }^{4}$.

Observem, doncs, un gir cap a la provisió de solucions tecnològiques integrals, intensives en $\mathrm{R}+\mathrm{D}+\mathrm{I}$. Potser Barcelona no és en si mateixa una important font d'ingressos a través d'aquest gir cap al coneixement (sinó que els ingressos principals continuen venint del cicle tradicional de l'aigua), però sí que serveix com una sala d'exposició al món per mostrar i vendre aquest nou model intel-ligent de gestió hídrica, especialment en un context en què les grans companyies de serveis estan abandonant els grans contractes de subministrament tradicional a moltes parts del món. Si observem companyies com Suez Environnement (que de fet és la propietària majoritària d'Agbar), Veolia o la mateixa Acciona, observem que totes estan fent un gir cap als paradigmes de la ciutat intel.ligent per ampliar les seves àrees de negocis.

\section{Discussió}

Davant d'aquests canvis tumultuosos (i polèmics) en el cicle de l'aigua metropolità i regional, podem constatar l'establiment de dos monopolis privats: un per al cicle integral urbà de l'aigua (incloent-hi el sanejament) $i$ un altre en el subministrament en alta de l'aigua.

En aquest article s'argumenta que les importants inversions en el cicle hidrològic dels darrers vint anys, el finançament inadequat, les sequeres recurrents, els canvis en els patrons de consum combinats amb la situació actual d'interrupció del crèdit a les institucions públiques, i la imposició dels estrictes dèficits des del nivell europeu (i de retruc des de l'Estat) poden explicar en bona mesura el perquè de la situació crítica del sistema públic de gestió de l'aigua a Catalunya i d'aquestes reconfiguracions «inevitables». Les organitzacions i plataformes ciutadanes afegeixen un altre factor clau que ajuda a explicar aquestes reconfiguracions: la renúncia del sector públic a gestionar un bé comú com l'aigua. En una òptica metropolitana, la situació d'indefinició contractual, juntament amb el temor d'entrar en un «forat negre» de finançament, complementa l'explicació del perquè de la reconfiguració en baixa.

El que hem tractat d'il.lustrar en examinar el cicle de l'aigua urbà de Barcelona es pot estendre també al sud d'Europa, on el deute i la crisi financera s'utilitzen com a justificacions discursives per redibuixar de manera fonamental les relacions entre Estat, capital, medi ambient i ciutadania. I el cicle de l'aigua no és aliè a tals canvis. Gialis i col-legues (2011) relacionen, per exemple, les reformes del sector urbà de l'aigua a Grècia amb la reestructuració del sector de l'aigua a Europa i la resta del món. Així doncs, i basant el meu argument amb el que diu la geògrafa Karen Bakker (2010: 720), es pot argumentar que la reconfiguració del cicle de l'aigua a Barcelona no és només una expressió de la interacció entre les dinàmiques politicoeconòmiques i ambientals locals i nacionals existents, sinó també de les dinàmiques

4. <http://barcelonacatalonia.cat/b/?p=3716\&lang=CA>. 
multiescalars de reestructuració regulatòria, en aquest cas de les polítiques ambientals i econòmiques.

Es vol fer un èmfasi especial en el paper clau i paradoxal que ha tingut el medi ambient (vegeu March, 2013b per a una revisió sobre la neoliberalització del medi ambient) en la legitimació discursiva d'una major presència del capital privat en la gestió, en aquest cas, de l'aigua. Així, Karen Bakker (2007), partint del cas anglès i gal-lès de privatització del cicle hidrològic, argumenta que el sector de l'aigua s'ha reinventat com una indústria de serveis ambientals. En aquest sentit, aquesta autora argumenta que s'ha anat produint un canvi en les geometries de poder i que s'ha concedit més importància a les preocupacions ambientals que als drets dels treballadors o als dels consumidors i ciutadans. De manera molt sintètica, aquesta autora argumenta que «mentre que els costos socials de producció de l'aigua abans eren externalitzats des de l'esfera del ciutadà polititzat i absorbits pel medi ambient, ara els costos ambientals de la producció de l'aigua són externalitzats des de l'esfera d'un medi ambient capitalitzat i suportats pels consumidors» (2007: 112, traducció pròpia), que responen normalment amb baixades importants del consum.

Salvant les diferències en el model de participació privada i en la governança de l'aigua, podem afirmar que en certa manera a Barcelona ha tingut lloc una situació similar que queda especialment exemplificada en els darrers esdeveniments que han redibuixat el cicle de l'aigua metropolità i regional. Durant el segle xx, per superar l'escassetat i fer arribar l'aigua a «tothom» (ja que hi podien haver moltes desigualtats en l'accés en alguns casos) es van fer intervencions molt importants en el cicle hidrològic que van deteriorar de manera important els ecosistemes aquàtics, però també van tenir un impacte (negatiu) social molt important, traduït en el desplaçament forçat de poblacions negades pels pantans.

En el marc d'unes regulacions ambientals estrictes dictades a escala europea, en els darrers anys les preocupacions ambientals han virat cap al centre (almenys discursivament) de la planificació hídrica. En un context en què l'única manera de finançar les noves inversions (i el deute acumulat) es veu a través de la participació de capital privat (no només industrial, sinó també financer, que ha donat peu a una financerització dels serveis hídrics [vegeu March i Purcell, 2014]), els costos es traspassen als ciutadans a través d'augments continuats dels preus, com es pot observar en el cas de Barcelona en els darrers anys. Per al 2014 s'ha aprovat un augment del 4,9\% del preu de venda d'aigua per part d'ATLL. Aquest augment està determinat principalment per les condicions de licitació acordades amb la Generalitat (augment del 4,2\%), al qual se li suma un 0,7\% per cent més d'augment acordat l'octubre de 2013. D'altra banda, en l'àmbit metropolità també s'ha fixat un augment important del preu per al 2014, una mitjana del 8,5\%. El cànon de l'aigua també està previst que augmenti un $7,2 \%$.

Aquests augments sostinguts del preu poden tenir com a resultat amb el temps, i si la situació econòmica no millora, la "pobresa hídrica» d'una part de la població, que ja veiem que existeix en el cas de l'energia (Síndic de Greuges 
de Catalunya, 2013). Per evitar tals situacions, a l'àrea metropolitana s'ha introduït una tarifa social que suposadament ha de garantir l'accés a l'aigua. Serà necessari fer un seguiment d'aquestes noves estructures tarifaries per analitzar els efectes reals en la població.

Com argumenta el geògraf Erik Swyngedouw, si exceptuem alguns casos regionals i temporals puntuals (com els ocorreguts a Barcelona al llarg del segle xx), l'accés desigual a l'aigua és un fet «socialment i políticament construit i expressa relacions desiguals de poder politicoeconòmic que estan inserides [...] en les dinàmiques del cicle hidrosocial» (ídem; vegeu també Kaika, 2005 i Linton i Budds, en premsa). Així doncs, si Barcelona ha patit en les darreres dècades certs episodis d'escassetat (física) d'aigua, amb un component de producció social a causa de l'expansió del model suburbà, la combinació entre crisi econòmica, recuperació integral de costos i benefici privat podria tenir com a resultat casos d'escassetat (econòmica), pròpia d'altres èpoques (durant bona part del segle XIX, quan només tenien accés a l'aigua corrent les classes benestants) o d'altres geografies.

D'altra banda, per bé que els costos ambientals (derivats de les directives més estrictes) es traslladin a l'esfera social, també s'estan desplaçant a altres esferes ambientals que queden a l'ombra d'aquestes regulacions. Per exemple, per disminuir impactes sobre recursos tradicionals (rius) i evitar més intervencions en aquests, s'ha donat un impuls important al dessalatge, que pot comportar una altra sèrie de problemàtiques ambientals (entre les quals hi ha els elevats costos energètics i les emissions de gasos d'efecte hivernacle).

\section{Conclusions}

Les solucions en què guanya tothom rarament existeixen en el seu model ideal. Pot guanyar el medi ambient i el capital, el capital i la ciutadania (o menys freqüentment la ciutadania i el medi ambient), però difícilment, en el marc politicoeconòmic en què estem immersos, poden guanyar tots tres alhora amb la mateixa intensitat i de manera equilibrada. Aquest article no s'ha d'entendre com un al-legat contra les polítiques ambientals i la millora de la qualitat dels nostres ecosistemes, que finalment repercuteixen molt positivament en el benestar dels ciutadans (o teòricament ho haurien de fer de manera equitativa). Tot al contrari, el que es vol exposar és la necessitat de repensar les relacions entre ciutadania, medi ambient, estat i capital, i explorar models alternatius que ens permetin gestionar els recursos d'ús comú (vegeu Ostrom, 1990). Aquests nous models haurien de superar la separació conceptual entre el cicle hidrològic i els processos socials, polítics i econòmics que el sostenen (Swyngedouw, 2013; Linton i Budds, en premsa) i plantejar noves relacions politicoecològiques més equitatives (Bakker, 2007), que permetin una participació activa i inclusiva de la ciutadania en la presa de decisions (Parés, 2011).

Evidentment, els mecanismes econòmics i el mercat tenen un rol a jugar en la gestió de l'aigua, però haurien d'estar supeditats a les necessitats ciutadanes i del medi ambient. Han de ser socialment justos repartint equitativament els costos de la millora ambiental, sense traslladar els costos als ciutadans més 
desfavorits, que són els que pateixen més cruament la crisi econòmica i que ja tenen comportaments ambientals molt austers. Tanmateix, la necessitat de mantenir mínimament les xifres d'un negoci ara per ara molt problemàtic fa que aquests supòsits no es compleixin.

\section{Agraïments}

Hug March ha rebut el suport d'un ajut postdoctoral Juan de la Cierva (convocatòria 2011) finançat pel Ministeri d'Economia i Competitivitat.

\section{Referències bibliogràfiques}

Aldomà-BuixadÉ, I. (2012). «Del conflicte d'usuaris a la confrontació política passant per l'autoafirmació regional. A propòsit de la crisi de la sequera del 2008 a Barcelona i els transvasament». Treballs de la Societat Catalana de Geografia, 74, 11-39.

Àrea Metropolitana de Barcelona (AMB) (2013). Dades ambientals metropolitanes 2012. Barcelona: Àrea Metropolitana de Barcelona.

BAKKER, K. (2003). «Archipelagos and networks: urbanization and water privatization in the South». The Geographical Journal, 169 (4), 328-341.

- (2005). «Neoliberalizing Nature? Market Environmentalism in Water Supply in England and Wales». A: Heynen, N.; McCarthy, J.; Prudham S. i Robbins P. (eds.). Neoliberal Environments: False promises and unnatural consequences. Londres i Nova York: Routledge, 101-113.

- (2007). «The 'Commons' versus the 'Commodity': Alter-globalization, Anti-privatization and the Human Right to Water in the Global South». Antipode, 39 (3), 430-455.

- (2010). «The limits of 'neoliberal natures': Debating green neoliberalism». Progress in Human Geography, 34, 715-735.

Balasch, L. (2012). «Agbar, una gestió il.legítima de l'aigua». A: PalÀ, R. i Picazo, S. Anuari Media.cat. Els silencis mediàtics del 2011. Barcelona: Mèdia.cat, 19-25.

Budds, J. i Mcgranahan, G. (2003). «Are the debates on water privatization missing the point? Experiences from Africa, Asia and Latin America». Environment and Urbanization, 15, 87-114.

Domene, E. i Saurí, D. (2012). «Water, public responsibility and equity: The Barcelona 'water war' of the 1990s». A: BARRAQuÉ, B. Urban Water Conflicts. París: Unesco Publishing, CRC Press, 33-38.

Domènech, L. (2011). «Rethinking water management: From centralised to decentralised water supply and sanitation models». Documents d'Anàlisi Geogràfica, 57 (2), 293-310.

Domènech, L.; March, H. i Saurí, D. (2013). «Degrowth initiatives in the urban water sector? A Social Multi-criteria Evaluation of non-conventional water alternatives in Metropolitan Barcelona». Journal of Cleaner Production, 38, 44-55.

DOMÈNeCH, L. i SAURí, D. (2010). «Socio-technical transitions in water scarcity contexts: Public acceptance of greywater reuse technologies in the Metropolitan Area of Barcelona». Resources, Conservation and Recycling, 55 (1), 53-62.

European Environment Agency (EEA) (2010). Changes in wastewater treatment in Southern European countries between 1980s and 2007. Copenhaguen: European Environment Agency. 
Gialis, S.; Louka, A. i Laspidou, C. S. (2011). "Theoretical perspectives and empirical facts on water sector privatization: the Greek case against European and global trends». Water Resources Management, 25, 1699-1719.

Global Water Intelligence (GWI). (2012a). "Counting the monopoly money». Global Water Intelligence, 13 (10) (octubre 2012). En línia.

- (2012b). «Opposition grows to Agbar's home rule». Global Water Intelligence, 13 (10) (octubre 2012). En línia.

Gorostiza, S.; March, H. i Saurí, D. (2013). «Servicing customers in revolutionary times: the experience of the collectivized Barcelona Water Company during the Spanish Civil War». Antipode, 45 (4), 908-925.

Hall, D. i Lobina, E. (2007). «International actors and multinational water company strategies in Europe, 1990-2003». Utilities Policy, 15 (2), 64-77.

KAIKA, M. (2005). City of flows: modernity, nature, and the city. Nova York: Routledge.

Linton, J. i Budds, J. "The hydrosocial cycle: Defining and mobilizing a relational-dialectical approach to water». Geoforum. En premsa. <http://dx.doi.org/10.1016/j.geoforum.2013.10.008>.

March, H. (2010). Urban Water Management and Market Environmentalism: A Historical Perspective for Barcelona and Madrid. Bellaterra: Universitat Autònoma de Barcelona. Tesi doctoral.

- (2013a). «Taming, controlling and metabolizing flows: Water and the urbanization process of Barcelona and Madrid (1850-2012)». European Urban and Regional Studies. <http://dx.doi.org/10.1177/0969776412474665>

- (2013b). «Neoliberalismo y medio ambiente: una aproximación desde la geografía crítica». Documents d'Anàlisi Geogràfica, 59 (1), 137-153.

March, H. i SAurí, D. (2013a). «The unintended consequences of ecological modernization: debt-induced reconfiguration of the water cycle in Barcelona». Environment and Planning A, 45 (9), 2064-2083.

- (2013b). "La sequera del 2007-2008 a la ciutat de Barcelona: gènesi, gestió i resposta ciutadana». Treballs de la Societat Catalana de Geografia, 76, 309-326.

March, H. i Purcell, T. (2014). «The muddy waters of financialisation and new accumulation strategies in the global water industry: The case of Agbar». Geoforum, 53, 11-20.

Martín Pascual, M. (2009). Barcelona: aigua i ciutat. Barcelona: Fundació Agbar i Marcial Pons Edicions Jurídicas y Sociales, SA.

Ostrom, E. (1990). Governing the Commons: The Evolution of Institutions for Collective Action. Nova York: Cambridge University Press.

PArés, M. (2011). «River Basin Management Planning with Participation in Europe: From Contested Hydro-politics to Governance-Beyond-the-State». European Planning Studies , 457-478.

Síndic de Greuges de Catalunya (2013). Informe sobre la pobresa energètica a Catalunya. Barcelona: Síndic de Greuges de Catalunya.

Swyngedouw, E. (2013). «UN Water Report 2012: Depoliticizing Water». Development and Change, 44 (3), 823-835.

Diaris consultats

Ara

El Pais

La Vanguardia 